\title{
Olfactory Reference Syndrome: Case Report
}

\section{Haica $C^{*}$}

Faculty of Psychology and Educational Sciences, Hyperion University, Romania

*Corresponding author: Haica C, Clinical Psychologist, CBT Psychotherapist, Hyperion University, Romania, Email: cristianahaica@yahoo.com

\section{Case Report}

Volume 5 Issue 2

Received Date: December 20, 2021

Published Date: December 30, 2021

DOI: $10.23880 / \mathrm{mhrij}-16000158$

\section{Abstract}

Olfactory reference syndrome (ORS) has been mentioned in DSM-5 in "Other Specified Obsessive-Compulsive and Related Disorder" as a psychiatric condition characterized by persistent preoccupation about an offensive body odor, accompanied by embarrassment, shame and significant distress, avoidance behaviour and social isolation. We consider this case an illustrative one for ORS, one that outlines the necessity of clear diagnostic criteria for this condition and reiterate that ORS represents a unique cluster of symptoms that can be delineated as a separate diagnostic entity. ORS has been recognized in the psychiatric literature as a syndrome that occurs in patients from multiple regions of the world, causing clinically significant limitations in social and personal functioning, distress and marking social disability, which renders out case study all more relevant. We also suggest that CBT can be used successfully in the management of ORS.

Keywords: Olfactory Reference Syndrome; Social Anxiety; Body Dysmorphic Disorder; Depression; Delusional Disorder; CBT

Abbreviations: ORS: Olfactory Reference syndrome; MDD: Major Depressive Disorder; GAF: Global Assessment of Functioning; CBT: Cognitive Behavioural Therapy.

\section{Introduction}

Olfactory reference syndrome (ORS) is mentioned in the DSM-5 in the Appendix of Criteria Sets Provided for Further Study section on culture-bound syndromes. It implicitly refers to ORS under the term of taijin kyofusho (a type of other specified obsessive-compulsive and related disorder), related specifically to the jikoshu-kyofu, a diagnosis used in Japan as a subtype of taijin kyofusho ("interpersonal fear disorder" in Japanese) [1], that has as main symptom the concern that the person emits an offensive body odor. In ORS this concern differs from normal body odor concern, associated with embarrassment, shame, even distress in social situations, by the intensity of the symptomsexcessive obsessive concerns, maladaptive responses to these concerns, significant distress and impaired functioning [2]. Taijin kyofusho is characterized by anxiety about and avoidance of interpersonal situations due to the thought, feeling, or conviction that one's appearance and actions in social interactions (inappropriate gaze, stiff or awkward facial expression, body movements or having an offensive body odor) are inadequate or offensive to others. Individuals tend to focus on the impact of their symptoms and behaviors on others [3]. This conviction may have a delusional intensity.

This condition has been reported in various cultures outside Japan, in Asia, United States, Australia, New Zealand, Europe, Middle East, Africa and other societies that place a strong emphasis on the self-conscious maintenance of appropriate social behaviour in hierarchical interpersonal relationships (DSM 5). The DSM-5 also lists ORS as an example of an "Other Specified Obsessive-Compulsive and Related Disorder" [3]. There is a brief description of ORS's key clinical features, but not full diagnostic criteria or discussion. 


\section{Mental Health \& Human Resilience International Journal}

For over 100 years, hundreds of cases from around the world have been reported with this condition. In 1971 Phillips KA, et al. [4] defined the term olfactory reference syndrome as a separate group with consistent phenomenology, after characterizing a large case series and carefully considering the differential diagnosis [4]. It is still a little explored condition even if researchers shown more interest in it [5].

In International Classification of Diseases, 11th Edition (ICD-11), ORS is added as a new, separate disorder (6B22 Olfactory reference disorder) in the chapter of ObsessiveCompulsive or Related Disorders (WHO, 2018). ICD-11 (WHO, 2018) mention also the diagnostic criteria: persistent preoccupation with the belief that one is emitting a perceived foul or offensive body odour, unnoticeable or slightly noticeable to others and excessive self-consciousness about the perceived odour, often with ideas of reference. Patients engage in repetitive and excessive behaviours (repeatedly checking for body odour or checking the perceived source of the smell, or repeatedly seeking reassurance, excessive attempts to camouflage, alter, or prevent the perceived odour), or avoid social situations that increase distress about the perceived foul or offensive odour. It is also mentioned that the symptoms are sufficiently severe to result in significant distress or impairment in personal, family, social, educational, occupational or other important areas of functioning" (WHO, 2018). The insight is poor or absent, and for many patients this poor insight contributes to their reluctance to consider psychiatric treatment [6]. The correct diagnosis provided with psychiatric treatment led to significant improvement in daily functioning [7].

ORS may have some symptoms in common with several different disorders, such as body Dysmorphic disorder, social phobia, schizophrenia, hypochondriasis or delusional disorder, and it was considered as one of these disorders rather than being a distinct syndrome [8-10]. It is important to be taken into consideration that disorders such as ORS may have different, multifaceted presentations and can be associated with mixed clinical pictures, which makes it prone to misdiagnosis and treated as some other disorder, so that the desired treatment response may not be achieved. The case below illustrates ORS in a way that sustains this condition is a disorder with its own criteria, that need a specific therapeutic approach.

\section{The Case History}

The patient is a 34 years-old man, not married, living in a town, working as an officer. At the moment of evaluation, he had just been transferred at work in a special department - transfer that he considered to be a promotion. He is a hardworking and dedicated person at work, he likes very much the specific of his activity. In his family he is the elder of the two sons and the one who attended college (as his parents). He was living in an apartment alone, having no relationship at that moment.

\section{Motive of Presentation}

At his first visit the patient complained the following symptoms: depressive mood, sadness, social retreat and anxiety, lack of motivation, loss of interest or pleasure in social activities, insomnia, hypoprosexia and tiredness. Not as a reason for his coming into the clinician's office, but to explain the context, he mentioned that he had a problem with his body door that he couldn't overcome.

\section{History of the Current Problem}

From the anamnesis interview and the history of every symptom we note the following aspects: Social retreatbecause he was constantly preoccupied that his body emits an unpleasant odour, he avoided social interaction for fear the others will be disgusted by the odour (the smell he pretended the others felt was considered to be originated from one of his organs: mouth-halitosis, rectum - flatulence or bad skin odour. This belief is accompanied by prevalent ideas that the odour is noticeable to people around him and he also claimed that he intermittently smells this. Asked what proofs he had - he answered that the others gestures are relevant: sneezing, touching their nose, scratching the head or face, covering the face, as responses to his body odour. He interpreted my own eye scratching as a reaction to his odour, asking me "you feel this, too, do you, I'm sure you do".

This constant preoccupation caused a significant distress and impairment in functioning: he was avoiding social situations at the workplace and with new acquittances, he was engaging in frequent body washing-more than twice a day in weekdays, but not in weekend, repeatedly checking oneself for body odour, he was excessively laundering and perfuming his clothes, he avoided staying close to the people and speaking loudly because they could feel the smell of his body or mouth. For example, he was very anxious when his superior called him for one-to-one discussion, because he thought that if the superior finds out how bad his body odor is, he will be disgusted and maybe he will not send him in some important missions, so he asked his superior to meet online. He also avoided to sit together with his colleagues and would eat separately for the same reason. In his office tasks he tried to work alone, avoiding teamwork as much as he could. His social life outside of the office was limited to some dance classes he started few years back, where he had the same partner always-"who is so used to my body odor, so that she never complains". He had no interest in extending his social life. 


\section{Mental Health \& Human Resilience International Journal}

Depressive mood, sadness, worthlessness and the lack of motivation to do other things than (controlling the body odor) are explained by the patient as normal, considering his condition: "how can I be happy with this situation? How can I try things involving people and avoid the embarrassing moment when they feel my smell?". The loss of pleasure and interest in any activity come from the idea that nothing is really worth to be done because even if he is going to accomplish the tasks properly, his work is not going to be appreciated at its real value because of the odor ("The people will be disgusted and they will under evaluate my work, so I have to work harder or more than others for the same result"). Insomnia - nearly every day and diminished ability to concentrate and work activities (tiredness) are related. He was sleeping less than 6 hours every night and was waking up very tired "when I go to sleep after midnight, when I finish my cleaning activities, I ruminate over the moments of the day when the others seemed to have felt the odor, so my sleep is flying, and I wake up at 6 a.m., tired".

Some of the symptoms (depressive mood, sadness, worthlessness, diminished ability to concentrate, social withdrawal) appeared in high school (around 18 years-old) and became more intense in the college -when he moved to the city to study (he left his parents' house for the first time, and lived in a campus). During this time, he lived in a context of school bulling (some of the students said he is a geek, and, noticing he is smelling himself often, they called him "stinky", and this name calling confirmed his suspicion about body odor). In the gymnasium and high school, he felt educational and familial pressure (especially from his father) to have high grades and to study harder, but in college he pressured himself to learn and be a very good student. He mentioned that he felt conditionally accepted and loved by the parents ("my parents love me when I have good grades, but it is normal, they are good and caring parents, they wanted all the best for me").

The worthlessness and some guilt feelings came from the shame of having the foul body odor so he considered himself a person full of defects, disappointing his parents, and also himself, a child trying to be perfect, but unable to be. He never made rituals to control or neutralize these persistent thoughts about his body odor, others than cleaning and perfuming. The body odor he believed he had was described as horrible coming from the mouth and stomach and/or anus. The odor was sometimes more intense than other times "because sometimes people don't notice it, and other times they do". The odor was not perceived by him all the time, but he knew it was there. At the moment of evaluation, he was working in a team of 20 people, suspecting they were aware of his unpleasant body odour and interpreted their behaviour, comments, gestures as relevant to his ideathey were sometimes covering their noses with their hands or touching their nose, they were using handkerchiefs or napkins, some of them are puffing, or were avoiding staying too close to him, they were opening the windows in the office, looking away, moving away from him (referential thinking).

He also had repetitive time-consuming behaviours during working days, such as showering 2-3 times a day, changing all his clothes every time he could, washing clothes after each usage, checking his mouth or underarms odor. His insight about the problem was poor, the intensity of his belief was delusional. He had no history of panic attacks, free-floating anxiety, or obsessive-compulsive symptoms. In the first year of college he experienced suicidal ideas, but he never considered committing suicide because this would disappoint his parents. He was comfortable with his appearance. No significant medical history - he had no other medical problems, but he constantly consulted dentists, gastroenterologists, proctologists, ear-nose-throat specialists, dermatologists - for the origin and treatment of his odor, but the treatments were ineffective and he was very dissatisfied with the doctors and their ability to cure him.

\section{Clinical Evaluation}

Mental status evaluation - the patient was conscious, cooperative, communicative, dressed appropriately, temporal and spatial oriented, auto and allopsychic. His mood was dysthymic (depressive), psychomotor drive was slightly depressed (slow body movements, arms alongside the body), and he was in a good logical-verbal contact. Eye to eye contact was initiated and maintained; the rapport was established easily. His attention was difficult to be sustained. Mood conveyed was dysthymic. The affect was congruent to the mood, constricted in range. His speech was continuous, coherent, and relevant. The patient was partially aware of his problems - he admitted something is not right considering he was tired, depressed, not sleeping enough and that he had too many thoughts about the way he is perceived by the others, but his insight about the disorder was poor.

The techniques used for psychological evaluation were: observation, anamnesis, structured and semi-structured clinical interview (The Structured Clinical Interview for DSM-5, Clinician Version, SCID-5-CV and SCID-5-PD for Personality Disorders) [11,12], and psychometric tests (FFPI, YSQ-S3, OPT, DAS-A, USAQ, ABS II, HAM-D, BAI). The psychometric tests results are:

- The Five-Factor Personality Inventory FFPI revealed: a low score in extraversion scale meaning he is an introvert, isolate, silent person; a low score on agreeableness - reflecting self-centred attitude: high score on conscientiousness - expressed in conformism, ability to control impulse, having a great sense of prioritization and organization; low score in emotional 


\section{Mental Health \& Human Resilience International Journal}

stability - meaning emotional instability [13].

- The Young Schema Questionnaire YSQ-S3 revealed the presence of maladaptive schemas (very high scores): emotional deprivation, abandonment/ instability, mistrust/abuse, social isolation/alienation, defectiveness/shame, social undesirability, failure, dependence/incompetence, enmeshment/undeveloped self-subjugation, self-sacrifice, emotional inhibition, unrealistic standards, insufficient self-control, approvalseeking/recognition-seeking, negativism/passivity [14].

- According to Beck AT, et al. [15,16] maladaptive schemas, dormant until triggered by stressful life events, create vulnerability to depression.

- The OPT (explanatory style and dispositional optimism)-a score of 28 specific to a pessimistic person he sees bad experiences as his own fault and impossible to change in the future and he has no control over them, the causes of negative events are external, unstable and specific. This attitude leads us to consider a learned helpless model $[17,18]$.

- Dysfunctional Attitude Scale DAS-A-with a score of 183-reflects a very high level of dysfunctional attitudes (a hallmark feature of depression) $[19,20]$.

- Unconditional Self-Acceptance Questionnaire USAQ revealing a low level of self-acceptance [21].

- Attitudes and Beliefs Scale ABS II-with a score of 165 , that means irrational modes of thinking such as demandingness, awfulizing, low frustration tolerance, self-downing and global evaluation [22].

These psychometric test tests used were some from the assessment platform CAS++ [23]. The Hamilton Depression Rating Scale (HAM_D) [24,25] result is a score of 29 specific to a very severe depression. Beck AT, et al. [26] Anxiety Inventory (BAI) result is a score of 31 suggesting a moderate level of anxiety.

\section{Evaluation of Cognitive, Conative, Affective and Behavioural Levels}

After clinical evaluation we can consider hypoprosexia but hyperprosexia toward any signs of others behaviour proving they perceive his body odours. His motivation is internal and affective (he is motivated by his needs motives and strongly influenced by the emotions and feelings). The dominant emotions are sadness, depressed mood, anhedonia, anxiety, low self-esteem, feelings of worthlessness and guilt (of not being good enough or as expected). These last far for more than 2 years.

- It was also noticed an anxious attachment.

- There has never been a manic or hypomanic episode or cyclothymic symptoms.

- The memory function is not altered.

- He had bradipsychia and referential thinking.
His activities were mostly sedentary, with office work and sedentary home activities after work. The patient wished to have a different kind of extra work activities (e.g., go for walks, run in the park, gym etc..) but he felt unable to do any of them because of the body odours and other people judgement and also feeling like he was lacking the energy. The daily activities were impaired by multiple activities of checking the smell and odour control.

\section{Evaluation of Psychophysiological Level}

The patient had initial insomnia-he used to stay awake till late at night ruminating negative thoughts, and wake up early in the morning, being tired during the day. The feeding instinct was altered by a poor appetite ("when I am this sad, I don't feel the hunger"), so he had been losing weight. He had no history of substance-use, not smoking, not drinking coffee or alcohol. He had never been to a psychologist or psychiatrist before that moment.

\section{Personality}

Personality traits suggested a Cluster $\mathrm{C}$ personality type: alienation, inadequacy, helplessness, passivity, and avoidance were prominent, fear of disappointing others, focus on details and order, perfectionism. ORD may be influenced by additive effects of multiple variables: internal factors such as perfectionistic tendencies and attribution of failure or rejection to body odor [2].

\section{Psychodiagnosis}

According to the psychological evaluation results we can conclude that There are confirmed the criteria for the following symptoms: Depression mood for most of the day, for more days than not, as indicated by subjective account, presence while depressed of insomnia and fatigue, low selfesteem, feelings of hopelessness, poor concentration that lasted for more than 2 years, never been without symptoms for more than 2 months at a time. The disturbance is not better accounted for by major depressive disorder (MDD) or MDD in remission. As we stated before, the patient has never had a manic episode, a mixed episode, hypomanic episode nor criteria for cyclothymia have been met, has never been a psychotic disorder, and it is not due to the direct physiological effects of a substance or general medical condition. Criteria confirmed belong to Persistent Depressive Disorder (dysthymia).

The persistent preoccupation with the belief that he is emitting a perceived foul body odor, experiencing excessive self-consciousness about the perceived odor, with ideas of reference, produced repetitive and excessive behaviors (checking for body odor, repeatedly seeking reassurance, 


\section{Mental Health \& Human Resilience International Journal}

excessive attempts to camouflage, or prevent the perceived odor, marked avoidance of social situations or triggers that increase distress about the perceived foul or offensive odor). These symptoms were severe, very distressful and produced significant impairment in personal, social, occupational areas of functioning. The symptoms are not better explained by any other entity from depression disorders, other obsessive-compulsive disorders, anxiety disorders or other feeding and eating disorders. These symptoms belong to Other Specified Obsessive-Compulsive and Related DisorderOlfactive Reference Syndrome (DSM-5), as ICD-11 mention: 6B22 olfactory reference disorder.

There were results indicating a disharmonic personality structure-Cluster C personality type, as result from evaluation with the questionnaires mentioned above (SCID 5 PD). The patient had great impairments in personality functioning having difficulties in empathy and intimacy areas, negative affectivity: anxiety, depression, guilt, shame, he avoided socioemotional experiences, withdrawal from interpersonal interactions, restricted affective experience and expression, behaviours that put him at odds with other people, but there are not met enough criteria for a personality disorder. If we consider the Alternative Model for Personality Disorders (DSM-5) we can identify a Moderate Personality Disorder and prominent traits of Negative Affectivity and Anankastia (ICD 11). Because of the early age of onset, we can presume the personality treats were influenced by the ORS. Global Assessment of Functioning (GAF) score is 35 because of major impairment in several areas: social, occupational functioning, behaviour was considerably influenced by his referential thinking.

\section{Management and Outcome}

Interventional tools used in this case management were: psych education, cognitive behavioural therapy and psychiatric medication (antidepressants) prescribed by a psychiatrist. First step in this kind of complex pathology is to establish and maintain an emphatic relation with the patient [27]. First three sessions were dedicated to an anamnestic interview and clinical psychological evaluation with the techniques and instruments mentioned above, and evaluation report presentation, being known that presenting and discussing the evaluation report, beside the feed-back value, can also have a therapeutic value by: improving self-esteem, reducing stress caused by symptoms [28,29], increasing hope for problem solving, and strengthen the therapeutic alliance [30,31], increasing adherence to treatment and clinician recommendations [32]. The anamnestic interview was centred on symptomatic evaluation and psychosocial evaluation: personal and social history, socio-economic status, psycho-social stressors, sexuality history, professional evolution, medical history, premorbid personality coping strategies and also psychopathological family history. The patient also visited a psychiatrist that recommended antidepressant medication for six months.

In the following 3 sessions we developed psychoeducation in order to make the patient aware of the disorders'manifestations, treatment possibilities for these disorders, compliance with the medical and psychological treatment, and of course ways of preventing progression, exacerbation and relapse of the problems. We had a number of 30 sessions of CBT (cognitive behavioural therapy) aiming identification of irrational thoughts and behavioural patterns that lead to or maintain the ORS symptoms, cognitive restructuration, reducing symptoms, enhance overall functioning, developing new effective coping strategies. Automatic thoughts related to people's reactions and core beliefs regarding feelings of inadequacy were discussed, as well. There were also used techniques of exposure to anxietyprovoking situations and response prevention, situational analysis (global thinking versus approaching one problem at a time), role-playing, analysing behavioural scenarios and also relaxation and mindfulness techniques.

Also, step by step, we developed conflict resolution skills, life skills training (to help him improve social interactions and increase the sense of self control of behaviour and thoughts).

After these sessions the patient considerably reduced the anxiety and the repetitive and excessive behaviours to check and camouflage body odor. He started to be more comfortable in placing himself close to other people without preoccupation about perceived smell, he also started to meet some friends ex colleagues from college and began expressing an interest in dating. Also, indices of depression and anxiety decreased to normal range, and he gained weight reaching the typical standards for his age and height. In the following 2 years there were organised follow up sessions: every two weeks in the first 6 months, as the referential thoughts continued, but they were less intense and he started to expresses doubt regarding the veracity of these perceptions. The following 6 months, the sessions were set for every three weeks in the following six months and once a month in the second year. After 2 years from the first presentation, he still needed 1-2 sessions of counselling support every time light symptoms reappeared, just to reinforce the principles learned.

\section{Discussion}

Our case of ORS had features suggestive of both depression and ORS. Mixed clinical picture is common in patients with ORS [8]. In this case Persistent Depressive Disorder was entirely secondary to ORS. Depressive symptoms are common in individuals with ORS $[33,34]$. We presume that even the personality traits were influenced by this syndrome. The treatment of ORS may involve psychotherapy and psychiatric 


\section{Mental Health \& Human Resilience International Journal}

treatment (antidepressant medication in our case). CBT has been used successfully in the management of ORS [35-38], Thomas E, et al. [4], and it is to be considered in every case, not only for cases that do not respond to medical treatments or where the compliance for medical treatment is very low. In our case, this approach (CBT and medication) yielded therapeutic success. These findings suggest that using CBT in the treatment of ORS is to be studied, and also more studies are needed for better understanding of the possible evolution, risk factors, prognosis, treatment and morbidity of ORS. Inclusion of ORS in ICD-11 will hopefully encourage research studies that will increase understanding and recognition of this condition, and hopefully the patients with ORS receive appropriate and timely referral to psychiatric and psychological services, avoiding unnecessary medical investigations and interventions.

\section{Conflict of Interest}

There are no conflicts of interest.

\section{References}

1. Suzuki K, Takei N, Iwata Y, Sekine Y, Toyoda T, et al. (2004) Do olfactory reference syndrome and jiko-shu-kyofu (a subtype of taijin-kyofu) share a common entity?. Acta Psychiatr Scand 109(2): 150-155.

2. Ren F, Zhou R, Zhou X, Schneider SC, Storch EA (2020) The latent structure of olfactory reference disorder symptoms: A taxometric analysis. Journal of Obsessive Compulsive and Related Disorders 27: 100583.

3. (2013) Diagnostic and Statistical Manual for Mental Disorders. In: $5^{\text {th }} \quad(E d n)$, American Psychiatric Association.

4. Phillips KA, Menard W (2011) Olfactory reference syndrome: demographic and clinical features of imagined body odor. General Hospital Psychiatry 33(4): 398-406.

5. Schmidt R, Haiduk M, Grocholewski A (2019) When you just can't "smell" yourself. Laryngo- rhino- otologie 98(3): 157-166.

6. Thomas E, Voges J, Chiliza B, Stein DJ, Lochner C (2017) Sniffing out olfactory reference syndrome. The South African Journal of Psychiatry 23: 1016.

7. Chernyak Y, Chapleau KM, Tanious SF, Dattilo NC, Diaz DR, et al. (2021) Olfactory Reference Syndrome: A Case Report and Screening Tool. Journal of Clinical Psychology in Medical Settings 28(2): 344-348.

8. Lochner C, Stein DJ (2003) Olfactory reference syndrome: Diagnostic criteria and differential diagnosis. J Postgrad
Med 49(4): 328-331.

9. Bhagat H, Bendre A, Dikshit R, De Sousa A, Shah N, et al. (2017) Olfactory reference syndrome treated with electroconvulsive therapy. Ann Indian Psychiatry 1(2): 129-131.

10. Özen ME, Aydin M (2019) Olfactory Reference Syndrome: A Separate Disorder Or Part Of A Spectrum. British Journal of Pharmaceutical and Medical Research 4(1): 1617-1625.

11. First MB, Williams JBW, Karg RS, Spitzer RL (2015) Structured Clinical Interview for DSM-5. American Psychiatric Association.

12. First MB, Williams J, Karg RS, Spitzer RL (2016) User's guide to structured clinical interview for DSM-5 disorders (SCID-5-CV). American Psychiatric Publishing pp: 1-170.

13. Hendricks AB (1997) Predicting Student Success with the Learning and Study Strategies Inventory. Unpublished Master's thesis.

14. Young JE (2005) Young Schema Questionnaire-Short Form 3 (YSQ-S3). Cognitive Therapy Center, New York, USA.

15. Beck AT (1972) Depression: Causes and treatment. Philadelphia. University of Pennsylvania Press.

16. Beck AT, Rush AJ, Shaw BF, Emery G (1979) Cognitive therapy of depression. Guildford Press, New York, USA.

17. Albu M (2006) Assessment of optimism using the OPT questionnaire. In: Yearbook of Petre Andrei University of Iaşi, Social Sciences, New Series, volume I, Iasi: European Institute Publishing House pp: 148-158.

18. Albu M (2005) A questionnaire to assess optimism. In: Studies and research in the field of socio-human sciences, Cluj-Napoca: Argonaut Publishing House 13: 9-18.

19. Weissman AN (1979) Assessing depressogenic attitudes: A validation study. Unpublished thesis, University of Pennsylvania.

20. Weissman A, Beck AT (1978) Development and validation of the dysfunctional attitude scale paper presented at the annual convention of the association for the advancement of Behaviour Therapy. Journal of Research and Development in Education 4(2): 33-41.

21. Chamberlain J, Haaga DAF (2001) Unconditional selfacceptance and psychological health. Journal of RationalEmotive \& Cognitive-Behavior Therapy 19: 163-176. 


\section{Mental Health \& Human Resilience International Journal}

22. DiGiuseppe R, Leaf R, Robin MW, Exner J (1988) The development of a measure of irrational/rational thinking. Presented at the World Congress on behaviour Therapy. Edinburgh, Scotland, pp: 1-6.

23. Miclea M, Porumb M, Cotârlea P, Albu M (2009) CAS++. Cognitrom Assessment System++. ASCR, Romanian Association of Cognitive Sciences pp: 1-139.

24. Hamilton M (1960) A rating scale for depression. J Neurol Neurosurg Psychiatry 23(1): 56-62.

25. Sharp R (2015) The Hamilton Rating Scale for Depression. Occup Med 65(4): 340.

26. Beck AT, Epstein N, Brown G, Steer RA (1988) An inventory for measuring clinical anxiety: Psychometric properties. J Consult Clin Psychol 56(6): 893-897.

27. Rizeanu S, Haica C (2020) Psychological counselling. Bucharest University.

28. Enea V, Dafinoiu I (2017) Psychological evaluation. Clinical Psychologist's Handbook. Polirom Publishing House.

29. Newman ML, Greenway P (1997) Therapeutic effects of providing MMPI-2 test feedback to clients at a university counseling service: a collaborative approach. Psychol Assess 9(2): 122-131.

30. Hilsenroth MJ, Peters EJ, Ackerman SJ (2004) The development of therapeutic alliance during psychological assessment: Patient and therapist perspectives across treatment. J Pers Assess 83(3): 332-344.
31. Rizeanu S (2013) Introduction to psychotherapy. Bucharest University.

32. Kraupl Taylor DO, Ng AV, Low J (2008) Therapeutic assessment based on cognitive-analytic therapy for young people presenting with self-harm: Pilot study. Psychiatric Bulletin 32(11): 423-426.

33. Sofko C, Tremont G, Tan JE, Westervelt H, Ahern DC, et al. (2020) Olfactory and Neuropsychological Functioning in Olfactory Reference Syndrome. Psychosomatics 61(3): 261-267.

34. Aftab A, Latorre S (2017) Geriatric-Onset Olfactory Reference Syndrome Successfully Treated with Duloxetine and Memantine. Prim Care Companion CNS Disord 19(2): 16102011.

35. Kizu A, Miyoshi N, Yoshida Y, Miyagishi T (1994) A case with fear of emitting body odour resulted in successful treatment with clomipramine. Hokkaido Igaku Zasshi 69(6): 1477-1480.

36. Lochner C, Stein DJ (2003) Olfactory reference syndrome: diagnostic criteria and differential diagnosis. Journal of Postgraduate Medicine 49(4): 328-331.

37. Martin Pichora AL, Antony MM (2011) Successful treatment of olfactory reference syndrome with cognitive behavioral therapy: A case study. Cognitive and Behavioral Practice 18(4): 545-554.

38. Begum M, McKenna P (2011) Olfactory Reference syndrome: A systematic review of the world literature. Psychol Med 41(3): 453-461.

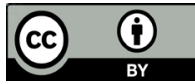

